\title{
Severe Labial Agglutination Release in a Postmenopausal Woman
}

\author{
Rebecca James, Anne Sammarco, David Sheyn, Sangeeta Mahajan \\ Department of Obstetrics and Gynecology, University Hospitals Case Medical Center, Cleveland, USA \\ Email: rebecca.james@uhhospitals.org
}

Received 3 July 2014; revised 3 August 2014; accepted 1 September 2014

Copyright (C) 2014 by authors and Scientific Research Publishing Inc.

This work is licensed under the Creative Commons Attribution International License (CC BY).

http://creativecommons.org/licenses/by/4.0/

(c) (i) Open Access

\begin{abstract}
Labial agglutination occurs when the labia minora have become fused in the midline through either filmy or dense adhesions, forming a raphe. This condition is typically seen in pre-pubertal girls; however, there have been cases reported in the literature of labial agglutination in postmenopausal and reproductive aged women. Labial agglutination has been associated with local irritation and inflammation in the setting of a hypoestrogenic state. Topical treatment is usually recommended prior to manual separation. However, some postmenopausal women have been refractory to conservative management, and surgery may then be required. We present a case of a 79-year-old Caucasian gravida 3 para 3 who was referred for treatment refractory labial agglutination for 3 years. The patient's complaints included a small trickle escaping from the introitus during urination and the sensation of little urinary control. The patient underwent an exam under anesthesia. Gentle blunt dissection with a lacrimal dilator easily separated the labia minora down the visible midline fusion line (raphe). Bimanual exam then revealed a 12-week-sized enlarged uterus confirmed on ultrasound to be an $8 \times 8 \times 7 \mathrm{~cm}$ irregular mass concerning for uterine cancer. Proceeding to an operative release of severe labial agglutination can relieve patient discomfort and frustration when estradiol therapy has failed. In addition to alleviating symptoms, releasing labial agglutination can also provide the gynecologist access to critical screening procedures such as cervical cytology or a bimanual exam, all of which could lead to a diagnosis or pre-cancerous or cancerous lesions.
\end{abstract}

\section{Keywords}

Labial Agglutination, Hypoestrogenic State

\section{Introduction}

Labial agglutination occurs when the labia minora have fused by formation of adhesions at the midline, which

How to cite this paper: James, R., Sammarco, A., Sheyn, D. and Mahajan, S. (2014) Severe Labial Agglutination Release in a Postmenopausal Woman. Open Journal of Obstetrics and Gynecology, 4, 822-825.

http://dx.doi.org/10.4236/ojog.2014.414114 
may be either filmy or dense, forming a raphe. This condition is most commonly seen in pre-pubertal girls and is often congenital; however, case reports in postmenopausal and reproductive aged women also exist [1]-[6]. In post-menarchal females fusion develops secondarily, rather than due to congenital malformation, the possible etiology of this may be a hypoestrogenic state, in conjunction with local irritation and inflammation [1]. Other postulated causes of agglutination include thinning of the vulvar mucosa, poor hygiene, lichen sclerosis, contact with urine, local infection, and mechanical irritants [5]. One study showed that biopsy of the labia of two patients reported chronic and acute inflammatory changes, indicating that inflammation may play a key role in the presence of a hypoestrogenic state to cause agglutination [5].

Labial agglutination can be asymptomatic, especially in pre-menarchal girls, making it difficult to estimate accurate incidence and prevalence. When symptoms are present in an older woman, they may include dyspareunia, urinary tract infections, hematocolpos, urinary incontinence, deviation or obstruction of urinary stream, and in one case report, association with pyosalpinx [4] [5] [7]. In contrast to the pediatric population in which the fusion usually involves only the labia minora, in postmenopausal women agglutination may also involve the labia majora [8]. Severe labial fusion can sometimes leave only a small pinhole through which urine can escape, and the vagina fills with urine causing urocolpos and dribbling. These findings can predispose the patient to ascending infections [7] [8].

We present a case report of a 79-year-old post-menopausal female with 3 years of labial agglutination and subsequent management.

\section{Case Report}

A 79-year-old Caucasian female was referred to our unit for a long term history of labial agglutination. She initially presented three years ago to a gynecologist with vague vaginal complaints and was given vaginal estradiol cream. She used the cream until new health issues developed including pneumonia and a urinary tract infection, interrupting use. After a second gynecologist evaluated the patient and patient was restarted on a vaginal estradiol regimen, the patient again fell out of the habit of use secondary to difficulty with insertion. A third gynecologist examined the patient and stated having “... never seen something like that before”, and sent her to our unit as a referral. During our evaluation she reported a history of a small trickle escaping from the introitus during urination and the sensation of little urinary control. Although she had resumed topical estradiol use for 6 weeks prior to her visit to our office, she reported little to no improvement in her symptoms.

Her past medical history was significant for HER-2 positive breast cancer status post mastectomy, hypertension, osteoarthritis, glaucoma, and recent pneumonia. She was not currently and did not anticipate becoming sexually active in the future.

On physical exam the urethra was unidentifiable given complete agglutination of the labia minora from clitoris to the posterior forchette. A pinpoint opening about two thirds of the way caudally appeared to be the urinary exit site (Figure 1). On rectal exam a patent vaginal canal was palpated. Her visible external genitalia were free of typical cutaneous signs of lichen sclerosis or lichen planus.

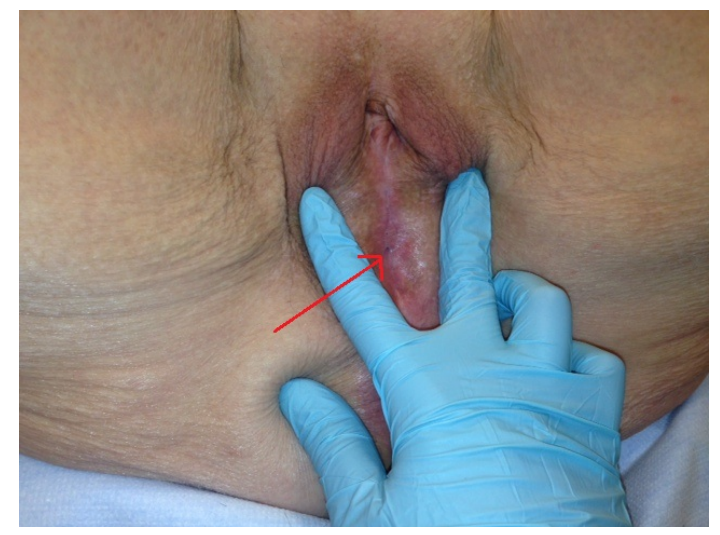

Figure 1. Severe labial agglutination with complete fusion of the labia minora from the clitoral hood to the posterior fourchette. 


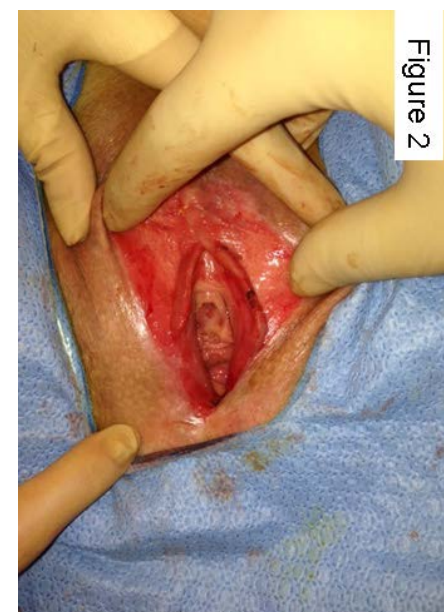

Figure 2. Post-operative opearance with separation of the labia minora.

The patient underwent an exam under anesthesia. A lacrimal dilator was placed in the 2 millimeter opening and using gentle blunt dissection we were able to easily separate the labia minora along the visible midline fusion line (raphe). No sharp dissection was required. The interior aspects of the minora and introitus were erythematous consistent with postmenopausal atrophy, but otherwise within normal limits. Genitourinary inspection revealed an atrophied, but otherwise normal vaginal introitus and urethra (Figure 2). Bimanual exam revealed a 12-week-sized uterus. The patient recovered well post-operatively and was discharged home the same day with topical vaginal estradiol and a transvaginal ultrasound referral. The report revealed an $8 \times 8 \times 7 \mathrm{~cm}$ irregular mass concerning for uterine cancer. Although the patient has presented for her gyn oncology referral appointment, she has not followed up for further treatment at this time.

On follow-up evaluation the patient has been able to maintain an open introitus and normal urine flow with continued use of vaginal estrogen cream and simultaneous vaginal dilation for 20 minutes 3 nights per week.

\section{Discussion}

Labial agglutination previously is typically seen in the pediatric population, is usually asymptomatic and may be managed expectantly or with topical estrogen, often resolving after menarche [9]. However, postmenopausal women can experience significant symptoms including urocolpos, inability to void, infections, and interference with sexual activity. Awareness of secondary labial agglutination and its visual presentation is critical in offering management without delay to this patient population.

In symptomatic postmenopausal women there are typically four methods for treatment including: 1) blunt or sharp separation with local, regional or general anesthesia, 2) manual separation without anesthesia, 3) topical estrogen or steroids, and 4) oral estrogen [1] [5]. Brisk manual separation without anesthesia, however, is not recommended as this can be very uncomfortable for the patient.

It is recommended that topical treatment be attempted prior to manual separation, however some postmenopausal women have been refractory to conservative management, and surgery may then be required. If manual separation is required, topical estrogen and/or steroids are then used to ensure separate healing of the labia [5].

In long-standing cases of labial agglutination it is also important to remember to perform a complete assessment of the reproductive organs as labial agglutination may limit evaluation or mask common findings that lead to the diagnosis of malignancy such as vaginal bleeding or a palpable mass.

\section{References}

[1] Lentz, G.M., Lobo, R.A., Gershenson, D.M. and Katz, V.L. (2012) Comprehensive Gynecology: Expert Consult Online and Print. 6th Edition, Elsevier, Mosby.

[2] Norbeck, J.C., Ritchey, M.R. and Bloom, D.A. (1993) Labial Fusion Causing Upper Urinary Tract Obstruction. Urology, 42, 209-211. http://dx.doi.org/10.1016/0090-4295(93)90650-Y

[3] Kuo, D.M., Chuang, C.K., Hsieh, C.C., Liou, J.D., Chen, K.C. and Hsieh, T.T. (1998) Labial Fusion in a Thirty- 
Year-Old Woman. Acta Obstetricia et Gynecologica Scandinavica, 77, 697-698.

[4] Chang, C.H., Fan, Y.H., Lin, A.T.L. and Chen, K.K. (2012) Bladder Outlet Obstruction Due to Labial Agglutination. Journal of the Chinese Medical Association, 75, 40-42. http://dx.doi.org/10.1016/j.jcma.2011.10.006

[5] Pulvino, J.Q. and Flynn, M.R. (2008) Urinary Incontinence Secondary to Labial Agglutination. International Urogynecology Journal, 19, 253-256. http://dx.doi.org/10.1007/s00192-007-0415-8

[6] Hatada, Y. (2003) Two-Step Surgical Approach to Labial Adhesions in a Postmenopausal Woman. Acta Obstetricia et Gynecologica Scandinavica, 82, 1054-1055. http://dx.doi.org/10.1034/j.1600-0412.2003.00028.x

[7] Tsianos, G.I., Papatheodorou, S.I., Michos, G.M., Koliopoulos, G. and Stefos, T. (2011) Pyosalpinx as a Sequela of Labial Fusion in a Post-Menopausal Woman: A Case Report. Journal of Medical Case Reports, 5, 546. http://dx.doi.org/10.1186/1752-1947-5-546

[8] Chuong, C.J. and Hodgkinson, P. (1984) Labial Adhesions Presenting as Urinary Incontinence in Postmenopausal Women. Obstetrics Gynecology, 64, 81s-84s. http://dx.doi.org/10.1097/00006250-198409001-00020

[9] Kumetz, L.M., Quint, E.H., Fisseha, S. and Smith, Y.R. (2006) Estrogen Treatment Success in Recurrent and Presistent Labial Agglutination. Journal of Pediatric Adolescent Gynecology, 19, 381-384.

http://dx.doi.org/10.1016/j.jpag.2006.09.008 
Scientific Research Publishing (SCIRP) is one of the largest Open Access journal publishers. It is currently publishing more than 200 open access, online, peer-reviewed journals covering a wide range of academic disciplines. SCIRP serves the worldwide academic communities and contributes to the progress and application of science with its publication.

Other selected journals from SCIRP are listed as below. Submit your manuscript to us via either submit@scirp.org or Online Submission Portal.
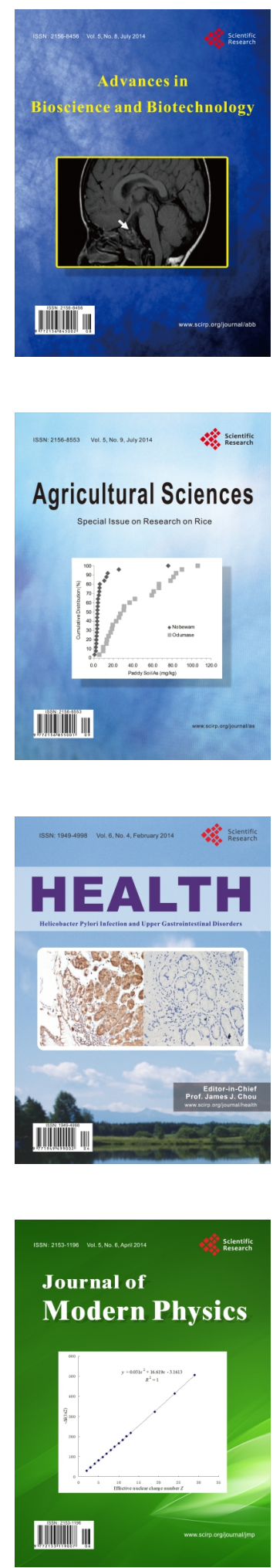
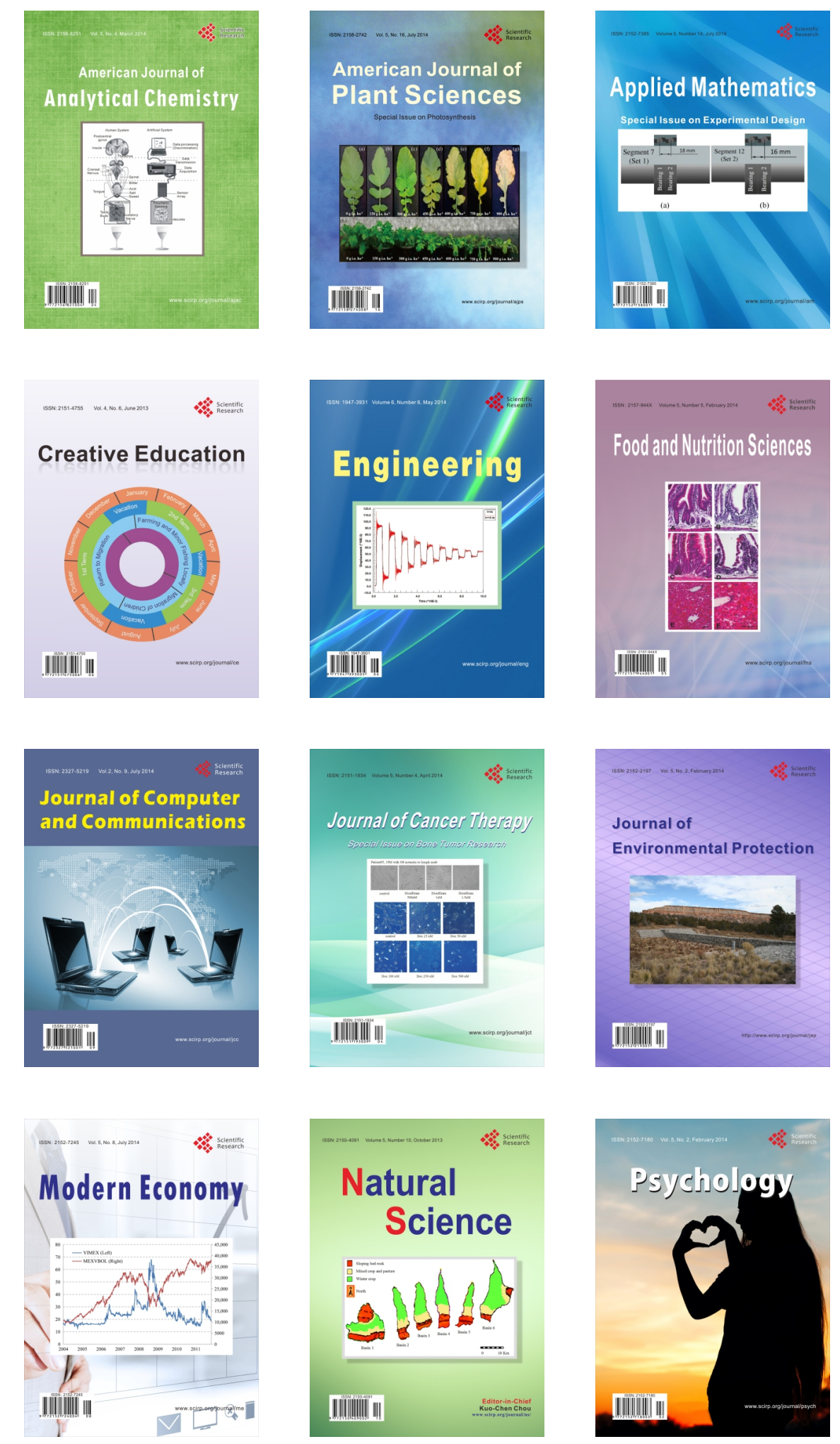